\title{
NOTAS SOBRE O VIÉS UTILITARISTA DA EDUCAÇÃO CONTEMPORÂNEA E O MODELO DA PAIDEIA
}

\section{NOTES ABOUT THE UTILITARIAN BIAS OF EDUCATION IN CONTEMPORARY SOCIETY AND THE CONCEPT OF PAIDEIA}

\author{
BRASILEIRO, Fabiana Neiva Veloso \\ fabianaveloso@unifor.br \\ UNIFOR - Universidade de Fortaleza \\ LOPES, Marlo Renan Rocha \\ marlorenanlopes@gmail.com \\ UNIFOR - Universidade de Fortaleza \\ MARTINS, José Clerton de Oliveira \\ jclertonmartins@gmail.com \\ UNIFOR - Universidade de Fortaleza
}

RESUMO O objetivo deste artigo é tecer algumas notas sobre o viés utilitarista da Educação na contemporaneidade e os valores caros à formação humana no modelo da Paideia, buscando, com esses apontamentos, problematizar o cenário educacional formal de hoje. Opta-se por uma abordagem qualitativa de cunho descritivo e exploratório, com uma revisão bibliográfica dos temas abordados: contemporaneidade, a Educação de viés utilitarista no contexto contemporâneo e a Educação grega clássica na perspectiva da Paideia. Discute-se que a Paideia resguarda determinados princípios norteadores de educação que podem ser de grande valia para se refletir sobre as práticas educativas atuais, muitas delas voltadas para o tecnicismo em detrimento de uma formação integrativa de ser humano.

PALAVRAS-CHAVE: Contemporaneidade. Educação. Paideia.

ABSTRACT The purpose of this article is to make some notes on the utilitarian bias of education in contemporary society and the values so dear to the human formation in the Paideia model, searching, with these notes, discuss the formal educational setting today. It was chose the qualitative approach of descriptive and exploratory nature, based on a literature review of the topics covered: the contemporary, utilitarian bias of education in the contemporary context and classical Greek education in view of Paideia. It is argued that the Paideia protects certain guiding principles of education that can be of great value to reflect on the current educational practices, many of them focused on the technicality rather than a full human being formation.

KEYWORDS: Contemporaneity. Education. Paideia.

\section{INTRODUÇÃO}




\section{Atos de Pesquisa em Educação - ISSN 1809-0354 \\ Blumenau, v. 13, n.2, p.212-228, mai./ago. 2018 \\ DOI: http://dx.doi.org/10.7867/1809-0354.2018v13n2p-212-228}

As últimas décadas testemunharam, de forma recorrente, uma notável dificuldade do sistema educacional em formar o jovem e prepará-lo para a vida. Isto porque o que se denomina Educação atualmente parece enfatizar excessivamente a preparação do aluno para o mercado de trabalho, esquecendo-se da sua formação em um plano simultaneamente social e individual, em que os valores da civilidade, do respeito ao outro e do direito de ser configuram-se como prioritários (CORTELLA, 2011; SALIS, 2011). Atendendo a uma demanda social provinda principalmente de pais de alunos atentos aos sistemas de avaliação impostos pelos programas escolares que possibilitam o ingresso nos cursos superiores, as escolas preocupamse, cada vez mais, em preparar a criança e o jovem para o exercício de um trabalho baseado na profissão escolhida, que envolva a capacitação técnica adquirida e a remuneração condizente com tal formação (COSTA, 2003). Tal fato acaba por gerar um aumento significativo da carga horária de aulas que, em geral, transmitem um conhecimento técnico através de uma metodologia mecanicista, muitas vezes sem sentido para o educando.

Grande parte das escolas - em especial as de grande porte - busca elevar o status de seus níveis de ensino promovendo alunos que se destacam pelas suas habilidades com o conteúdo das disciplinas, o que enfatiza a preocupação destas instituições em tornar os educandos aptos ao objetivo principal de concorrer em um certame. Essa realidade pode ser observada nas propagandas de grandes escolas que enfatizam, como fator diferencial, sua competência em capacitar alunos para se destacarem nos exames que finalizam o Ensino Médio e que garantem acesso a determinados cursos superiores (RODRIGUES, 2002).

A prioridade atual do ensino, portanto, parece ser a busca por uma aprovação a qualquer custo nestes exames e uma pretensa excelência profissional por parte do aluno. Estas metas são observadas principalmente a partir da segunda metade do Ensino Fundamental brasileiro até o final do Ensino Médio, quando os princípios de uma educação mais integrativa são desconsiderados, relegados a segundo plano ou mal trabalhados por educadores e gestores. Aqui, entende-se a educação integrativa como aquela voltada para a formação dos aspectos sociais, psicológicos, pedagógicos e afetivos, que estimula o aspecto cognitivo sem esquecer a 


\section{Atos de Pesquisa em Educação - ISSN 1809-0354 \\ Blumenau, v. 13, n.2, p.212-228, mai./ago. 2018 \\ DOI: http://dx.doi.org/10.7867/1809-0354.2018v13n2p-212-228}

necessidade do desenvolvimento das relações humanas, da arte e dos valores de cooperação (GRAVATÁ, 2013).

Nesses moldes, a Educação contemporânea nos remete a uma concepção majoritariamente utilitarista que, como anota Russel (2002), ignora as necessidades reais dos sujeitos, ocupando-se em treiná-los com mero propósito de qualificação profissional, esquecendo-se, desta maneira, dos pensamentos e desejos pessoais desses indivíduos. Assim, mesmo com propostas supostamente inovadoras que a contemporaneidade oferece para a Educação, o projeto educacional tradicional da sociedade de hoje parece ser um intento destinado à ineficácia, uma vez que se volta em grande parte para a transmissão e a retenção de conhecimentos e informações, como se estes fossem capazes de realizar uma formação integrativa e preparar o aluno para o desafio da convivência e do exercício da civilidade.

Nesse contexto, de acordo com Lipovetsky (2004), em virtude da ênfase conferida à formação para um futuro imediato, observa-se a rápida expansão do consumidor escolar: o crescimento dos serviços de aulas particulares, dos cursos extracurriculares e de uma série de outras atividades a fim de preparar a juventude para a vida profissional. Segundo Aquino e Martins (2007), a sociedade contemporânea não privilegia a orientação para ser/existir em um tempo de "nada fazer", de modo que o tempo livre se apresenta cada vez mais reduzido, e não se percebe um encaminhamento de viés educacional para o uso adequado do tempo um fator de vital importância para a constituição de uma pessoa saudável em termos psíquicos e físicos.

$\mathrm{Na}$ Antiguidade, o potencial valor humano de uma vida educativa integralista e contemplativa era frequentemente cultivado como prioridade. Uma das atividades fundamentais para a criação e a consolidação do pensamento filosófico na Grécia Clássica era, precisamente, a formação integrativa do ser humano, fomentando a consciência do direito de ser e agir politicamente de acordo com os princípios de cada pessoa. Os mestres, nas sociedades gregas, preparavam os jovens de acordo com princípios de aprimoramento da arte de ser verdadeiro, de ter a coragem de ser e assim revelar seus talentos e suas potencialidades. Nessa conjuntura, a Educação encontrava-se voltada para a formação do homem ético e não valorizava somente o acúmulo de conhecimentos considerados úteis (SALIS, 2008), mas principalmente a 
reflexão intensa sobre tais conhecimentos. A Paideia representava a formação de crianças e jovens em um plano ético individual e social com origem em si mesmo, baseado no respeito ao outro e no direito de ser, sendo possível porque a formação do caráter era um valor cultivado em primeiro plano.

A cultura grega, por exemplo, reconhecia o valor decisivo da Educação na vida social e individual e considerava a formação humana em sua integralidade respeitando o aspecto físico, intelectual, ético e estético da construção do conhecimento em planos individuais e coletivos (LUZURIAGA, 1979). Portanto, a Paideia - um conceito de complexa definição originado desta ênfase dada pelos gregos à formação integrativa e constante - parece-nos ser um aporte essencial para refletirmos sobre aspectos da Educação que, no cenário atual, podem não estar sendo trabalhados como parte crucial e necessária da formação humana.

O objetivo deste artigo reside em tecer considerações e apontamentos sobre o viés utilitarista da Educação na contemporaneidade, destacando certos valores caros à formação humana na Grécia Clássica - voltada para a formação integrativa, com o exercício da consciência cidadã e a orientação para a potência de ser, fundamentais na Paideia - que hoje parecem estar sendo pouco valorizados, quando não desconsiderados de todo. Assim, pretende-se esboçar reflexões sobre a educação contemporânea à luz da Paideia, destacando os aspectos importantes da formação integrativa que se destacavam na Antiguidade grega e provocando uma reflexão sobre a possibilidade de uma formação desse tipo no âmbito escolar contemporâneo.

Cabe lembrar que esta proposta de discutir alguns conceitos da Paideia não pode, em nenhum momento, ser traduzida como a mera tentativa de repetir um modelo do passado. O intuito de tais apontamentos é propiciar uma visão sobre os princípios norteadores deste modelo de educação de uma época anterior na nossa história a partir do olhar contemporâneo, atento às possibilidades que ele nos oferece no contexto atual.

Também importa ressaltar aqui que os processos educativos não ocorrem apenas em escolas: eles são inerentes à existência das pessoas numa determinada sociedade e acontecem à medida que os seres humanos se movimentam, compreendem, interpretam e transformam o mundo em que vivem. Esses processos 


\section{Atos de Pesquisa em Educação - ISSN 1809-0354 \\ Blumenau, v. 13, n.2, p.212-228, mai./ago. 2018 \\ DOI: http://dx.doi.org/10.7867/1809-0354.2018v13n2p-212-228}

educativos devem ser pensados a partir da realidade do grupo ao qual pertencem e do projeto de sociedade que este grupo engendra.

\section{MÉTODO}

Este artigo adota uma abordagem qualitativa de cunho descritivo e se utiliza de uma revisão bibliográfica sobre os principais temas abordados na discussão: a contemporaneidade enquanto momento sócio-histórico com atributos específicos; a Educação de viés utilitarista no contexto contemporâneo; e a Educação grega clássica na perspectiva da Paideia. Ao discorrer sobre esses temas, aponta-se uma proposta de articulação entre alguns valores da Paideia e a necessidade, que aqui se considera inadiável, de refletir sobre o viés utilitarista incompatível com a perspectiva da Paideia, mas de certa forma útil no modelo de sociedade pragmática voltada para o mundo do trabalho e que serve de base para a Educação dos dias atuais. As obras selecionadas para esta discussão foram retiradas das bases de dados dos portais de periódicos CAPES (Coordenação de Aperfeiçoamento de Pessoal de Nível Superior) e SCIELO (Scientific Eletronic Library Online), em consulta compreendida entre os anos 2000 e 2015.

Para a compreensão da contemporaneidade e de suas características mais determinantes, foi consultada a palavra-chave "contemporaneidade", privilegiando artigos que tratassem do conceito em questão. Pela frequência com que são citados e pela extensão de sua obra, foram selecionados Lipovetsky (2004), Beriain (2008) e Bauman $(2001 ; 2011)$ como os autores representantes desta temática, que debatem, respectivamente, o consumismo em excesso, a aceleração do tempo e a fragilidade das instituições e dos valores no mundo atual.

Para o debate sobre a Educação em seu viés utilitarista neste contexto, foram utilizadas, na consulta, as palavras-chave "Educação" e "Contemporaneidade", privilegiando trabalhos que problematizassem o caráter utilitário da educação em nossa sociedade contemporânea. Desta exploração, os autores selecionados para figurarem no debate do presente artigo foram Cortella (2011), Rodrigues (2002), Salis (2011; 2008), Tardif (2010), Larrosa (2002) e Russell (2002), dada a sua proximidade com os pontos de vista aqui abordados e defendidos. 
Atos de Pesquisa em Educação - ISSN 1809-0354

Blumenau, v. 13, n.2, p.212-228, mai./ago. 2018

DOI: http://dx.doi.org/10.7867/1809-0354.2018v13n2p-212-228

Por fim, para se refletir sobre os princípios norteadores da Paideia, a palavrachave utilizada para pesquisa foi "Paideia", privilegiando trabalhos que tratassem a definição do conceito e as características mais pronunciadas deste modelo educacional antigo. Desta exploração, selecionamos Jaeger (2011) e Salis (2008; 2011) pela frequência com que suas obras são citadas e pela afinidade com o debate aqui proposto.

\section{A CONCEPÇÃO UTILITARISTA DE EDUCAÇÃO NA CONTEMPORANEIDADE}

A fim de tecer algumas considerações sobre a Educação de viés utilitarista na contemporaneidade, é importante demarcar alguns dos atributos que caracterizam este momento sócio-histórico. Somente assim é possível compreender como esses atributos influenciam o contexto educacional atual e, ainda, como este pode ser repensado tomando-se como exemplo alguns princípios da Paideia.

O contexto societário contemporâneo é entendido como pluralista e em permanente mudança, envolvido num processo de globalização neoliberal com uma temporalidade apressada, marcada pela lógica da quantidade, da eficácia, do desenvolvimento econômico, social e tecnológico, pelas relações fluidas, instantâneas, pelo antagonismo entre os grupos e pelo hiperconsumo (BAUMAN, 2011; BERIAIN, 2008; LIPOVETSKY, 2004). Tal lógica é permeada pela cultura do mais rápido e do sempre mais e, junto a ela, por uma aceleração nos modos de vida; aceleração esta que se iniciou na Modernidade, quando o homem resolveu medir o tempo cotidiano e quantificar o tempo social, chegando a comercializar a própria noção de tempo (AQUINO; MARTINS, 2007).

Assim, as ações humanas passam a focar a produtividade, uma vez que o tempo adquire valor comercial. Somos cada vez mais exigidos a fazer mais no menor tempo possível, a agir sem demora e a mostrar resultados em curto prazo. Há um clima de pressão, em decorrência do reinado da urgência que permeia a sociedade contemporânea; e neste universo da pressa, na qual o vínculo humano é substituído pela troca rápida, organiza-se uma cultura de hiperatividade, de busca pelo desempenho que, pouco a pouco, estimula o individualismo (LIPOVETSKY, 2004). 


\section{Atos de Pesquisa em Educação - ISSN 1809-0354 \\ Blumenau, v. 13, n.2, p.212-228, mai./ago. 2018 \\ DOI: http://dx.doi.org/10.7867/1809-0354.2018v13n2p-212-228}

$\mathrm{Na}$ contemporaneidade, é observada a desintegração do tradicionalismo de certas instituições, como a família, a igreja e as comunidades, na medida em que a sociedade se transforma e essas transformações repercutem na desestruturação das relações entre seus membros (BAUMAN, 2001; 2011). As pessoas parecem estar mais próximas e, ao mesmo tempo, mais distantes; as relações são instantâneas, efêmeras, e se tornam escassas as formas de organização coletiva sendo cada vez mais encorajadas as trajetórias individualistas.

A preocupação crescente com o mercado de trabalho e com as incertezas que marcam os empregos na contemporaneidade muitas vezes faz com que as pessoas não consigam se posicionar criticamente sobre o que thes acontece e, assim, passam a viver uma vida sem sentido profundo. O engajamento no trabalho, tal como é visto atualmente, impede o ser humano de ter tempo para pensar, para contemplar e compreender as consequências da sua mobilização exclusiva para a produtividade - consequências que podem ser notadas nas catástrofes ecológicas do meio ambiente e nos sofrimentos causados pelo desconhecimento e esquecimento de si.

Conforme aponta Larrosa (2002), o mundo contemporâneo está repleto de informação; no entanto, cada vez mais os sujeitos estão carentes daquilo que o autor chama de experiência. Ela pode ser compreendida como aquilo que acontece e que toca o sujeito, e que, ao tocá-lo, ao vir ao seu encontro, forma-o e transforma. E se "a experiência e o saber que dela derivam são o que permite nos apropriarmos da nossa própria vida" (LARROSA, 2002, p. 27), tudo o que torna impossível ou dificulta a experiência impossibilita também a existência com sentido. Dentre os fatores que impossibilitam a experiência, o referido autor menciona o excesso de informação presente nos dias atuais, a falta de tempo, o apressamento e o excesso de trabalho.

No contexto escolar, é direcionada aos alunos uma grande quantidade de informações que, muitas vezes, não têm a ver com a realidade na qual eles vivem: trata-se de conteúdos que os educandos têm de reproduzir em avaliações rigorosas incapazes de fazer sentido para eles - ou, em outras palavras, que não se conectam diretamente com o mundo em que vivem. Na maioria das vezes, esses conteúdos são transmitidos em períodos curtos de aulas fragmentadas que, geralmente, não 


\section{Atos de Pesquisa em Educação - ISSN 1809-0354 \\ Blumenau, v. 13, n.2, p.212-228, mai./ago. 2018 \\ DOI: http://dx.doi.org/10.7867/1809-0354.2018v13n2p-212-228}

guardam relações de sentido umas com as outras e não possibilitam discussão, desenvolvimento do pensamento crítico e autonomia (RODRIGUES, 2002; MOSÉ, 2013).

Para os alunos contemporâneos da sociedade em redes e das relações fluidas, este tipo de ensino não é atrativo, e a escola - em vez de constituir um lugar pautado no desenvolvimento de relações que permitem a vivência de valores, a afetividade, o desenvolvimento do pensar e do agir preocupado com o outro, com a diversidade e com a sustentabilidade ambiental - é vista como um local entediante. Os alunos vivenciam situações e assimilam programas conteudistas que na realidade não satisfazem uma demanda própria, e por isso não fazem sentido e não contemplam a formação integrativa do ser humano (RODRIGUES, 2002; MOSÉ, 2013).

O excesso de informação e de trabalho, a falta de tempo e o apressamento demarcam não somente as relações sociais, mas também a relação da escola com o processo de formação humana. O processo educativo contemporâneo se detém na escolarização e na preparação excessiva do educando para o mercado de trabalho, deixando de lado a experiência do aprendizado como um fim em si mesmo (LARROSA, 2002; PUIG; TRILLA, 2004). Não seria impreciso afirmar, portanto, que nesse contexto a escola se volta para as demandas típicas da contemporaneidade: processar o máximo de informações no menor tempo possível; preencher todo tempo livre disponível considerado improdutivo; e fomentar a trajetória individual competitiva em detrimento dos esforços coletivos para a construção e a transmissão do conhecimento.

O conteúdo transmitido e adquirido ao longo dos anos de escolarização não parece se furtar a estas características da sociedade contemporânea - nem poderia, uma vez que a escola contemporânea é, por definição, fruto da contemporaneidade. Como acentua Bauman (2011), para esta sociedade, a ideia de que a Educação possa ser um "produto" destinado à apropriação e conservado para sempre é desanimadora, pois o mundo passa por transformações constantes e, cada vez mais, temos à disposição excesso de informações que desafiam continuamente a verdade do conhecimento existente até então. Em um mundo assim, o aprendizado tende a cumprir objetivos imprecisos, que se evaporam no instante em que são 
Atos de Pesquisa em Educação - ISSN 1809-0354

Blumenau, v. 13, n.2, p.212-228, mai./ago. 2018

DOI: http://dx.doi.org/10.7867/1809-0354.2018v13n2p-212-228

atingidos, tendendo a criar hábitos e rotinas que com o tempo se mostrarão infrutíferos, pois o que importa é a satisfação das necessidades que o mercado demanda enquanto "vida após escola".

Rodrigues (2002) considera que a maior parte das iniciativas e práticas consideradas prioritárias para a ação educativa no seio das sociedades contemporâneas desconsidera aspectos fundamentais a respeito da educação, porque reduzem o processo educacional à sua dimensão de escolarização.

A Educação, identificada com a Educação escolar, converteu-se em simples instrumento do pragmatismo, imediatismo e utilitarismo do mundo capitalista moderno. E por isto aprofunda-se e alarga-se o fosso entre o que deveria se constituir como essência do ato educativo e as práticas colocadas em andamento nos tempos modernos. (RODRIGUES, 2002, p. 15).

Nesse sentido, a restrição do conceito de Educação provoca uma restrição também do seu alcance. Os fins que the são atribuídos tendem a um contínuo empobrecimento conceitual - o viés utilitarista da educação acaba por desviar os educandos de seus reais interesses, atribuindo-lhes atividades que não têm relação com sua curiosidade investigativa. O que importa não são suas preferências e inclinações, mas as escolhas que lhes são impostas de fora para dentro, como aquelas determinadas pelo mercado e que impõem um férreo individualismo competitivo que dissolve a vida social, a cooperatividade e a solidariedade.

Em geral, existe uma enorme defasagem entre os objetivos ditos humanistas e democráticos e a ação pedagógica concreta do dia-a-dia. Os fins da Educação, no entanto, não têm sentido se separados da ação educativa propriamente dita, da mesma forma que não se pode viabilizar uma escola, ou um programa de ensino, sem uma definição precisa dos seus fins. Esses objetivos devem consistir, basicamente, não em conceber a Educação como ideia - pois ela se realiza aquém e além do trabalho sistemático da escola - mas precisar quais são as atividades, as ações do aluno e do professor no cotidiano escolar (PAVIANI, 2010).

No que concerne à Educação, é importante destacar o fato de que não apenas a escola e a família são agentes educativos: educa-se com apoio em muitas outras instituições, meios e âmbitos, nem sempre reconhecidos como especificamente educativos. Para Puig e Trilla (2004), ao se admitir os conceitos de Educação formal, não-formal e outros paralelos e similares, que ultrapassam os 
Atos de Pesquisa em Educação - ISSN 1809-0354

Blumenau, v. 13, n.2, p.212-228, mai./ago. 2018

DOI: http://dx.doi.org/10.7867/1809-0354.2018v13n2p-212-228

limites do que antes era considerado educação, permite-se integrar ao objeto das disciplinas pedagógicas o conjunto de âmbitos e intervenções em que se pode realizar Educação mediante o lúdico, por exemplo, com brinquedotecas, colônias de férias e animações socioculturais, entre outros.

Portanto, a escola no contexto contemporâneo compactua com a concepção utilitarista de educação (RUSSELL, 2002), segundo a qual esta deve prover as pessoas de conhecimento "útil", que deixa de ser visto como um bem em si mesmo ou como um meio de se criar uma perspectiva de vida humana e abrangente e se transforma em mera ferramenta de aptidão técnica.

\section{A PAIDEIA GREGA E A EDUCAÇÃO CONTEMPORÂNEA}

O modelo grego antigo da Paideia resguarda determinados princípios norteadores de formação humana que parecem ser de grande valia para se questionar acerca das iniciativas e práticas educativas atuais de viés utilitarista, comentadas no item anterior, voltadas para o tecnicismo e o instrumentalismo em detrimento de uma formação integrativa do ser humano.

Para os gregos, Educação e formação humana eram processos que tinham sentidos diferentes. A Educação possuía um sentido de techné, de um conjunto de conhecimentos e aptidões profissionais transmissíveis, enquanto a formação do homem envolvia a criação de um tipo ideal intimamente coerente e claramente definido (JAEGER, 2011; SALIS, 2011). A formação, portanto, não seria possível sem que se oferecesse ao espírito uma imagem do homem tal como deve ser, e, nesta, o fundamental era a beleza, no sentido normativo da imagem desejada, do ideal que, todavia, não poderia ser alcançado pela limitação natural do ser humano. A formação envolvia um exercício ético constante e se manifestava na forma integral do homem, na sua conduta e na sua atitude interior.

A Paideia, um dos principais conceitos dos quais derivou a Pedagogia, consistia na formação para a virtude e para a verdade, que objetivava formar um "homem obra de arte", ético e criador. A Paideia ocorria dos seis aos 18 anos e buscava a maturação ética que se fundava na constituição da consciência, não intelectual, mas ética, buscando o direito natural cósmico de nascer, viver e morrer 
com dignidade e honra. A Educação grega caracterizou-se por ser uma Educação que exercitava o cultivo da virtude e o desenvolvimento do caráter cidadão (JAEGER, 2011; SALIS, 2011).

$\mathrm{Na}$ Paideia, os mestres educavam as crianças e os jovens nos bosques porque entendiam que aprender em contato direto com o meio ambiente era o ideal, uma vez que, segundo eles, só fazia sentido refletir sobre a vida onde ela transbordava por todos os lados. Cada mestre se encarregava de uma dúzia de alunos, sendo que seus pais forneciam tudo de que necessitassem, de modo que o mestre não precisava se preocupar com a subsistência e poderia dedicar-se totalmente a seus alunos por aproximadamente 15 anos. Esses jovens aprendiam desde tarefas básicas da vida, como higiene pessoal, até as mais transcendentais, como o sentido da vida e da morte, a honra e a dignidade de viver e de morrer (SALIS, 2011).

Neste sentido, as primeiras escolas surgidas nas pólis gregas cultivavam uma proposta de educação que acontecia por meio do treinamento dos cidadãos para profissões consideradas úteis e rentáveis. A edificação humana era um âmbito que estava além das necessidades do emprego ou do trabalho, relacionada, portanto, ao conhecimento e à capacidade para o bem, sem outros fins. Eram espaços lúdicos, de jogos, de encontros onde o conhecimento se elaborava de forma espontânea, não estando atrelado a currículos, a conteúdos programáticos ou a um ambiente ou situação específica e controlada.

O aporte essencial da história da formação grega é o conceito de arete, que remonta a tempos mais antigos. O termo não encontra, porém, tradução na língua portuguesa, mas se aproxima do sentido da palavra virtude. Conforme Jaeger (2011), arete é a "expressão do mais alto ideal cavalheiresco, unido a uma conduta cortês e distinta, atrelada ao heroísmo guerreiro como possibilidade de expressão do sentido" (JAEGER, 2011, p. 25). Ela define a busca por uma existência coerente e determinada, que molda a concepção de vida que cada um pretende seguir no nível pessoal, sem abrir mão da responsabilidade pelo meio social. É no conceito de arete que se concentra o ideal de formação humana dessa época - e de momentos posteriores. 


\section{Atos de Pesquisa em Educação - ISSN 1809-0354 \\ Blumenau, v. 13, n.2, p.212-228, mai./ago. 2018 \\ DOI: http://dx.doi.org/10.7867/1809-0354.2018v13n2p-212-228}

Portanto, o entendimento da Paideia pressupõe a compreensão de como os gregos buscavam imprimir nos membros da sociedade a arete, de modo que pudessem se reconhecer como responsáveis e realizadores dos valores coletivos: nesse sentido, Paideia e arete não podem ser pensadas separadamente.

Sócrates educava por meio da palavra, não para impor ideias, mas para descobrir a verdade, e discordava de uma Educação excessivamente sujeita à influência utilitarista. Insistia nos valores morais do homem e acreditava que a arete não era patrimônio somente da aristocracia, uma vez que era passível de ser ensinada. Divergia dos sofistas em vários aspectos: para Sócrates, a Educação não devia ser uma profissão remunerada, nem devia ter um caráter prático, de proveito pessoal, e sim um caráter moral, ético. Para ele, o saber e o conhecimento não conduziam à virtude - dado que o saber e a virtude são idênticos. E o fim último da Educação era precisamente a virtude, o bem, a moral, e não servir ao Estado, como na Educação tradicional, nem tirar proveito individual, como para os sofistas (LUZURIAGA, 1979).

Para Platão, educar não era um processo que ocorria de fora para dentro: não constituía a mera transmissão de conhecimento, mas o despertar na pessoa o que ela já sabe, proporcionando ao corpo e à alma a realização do bem e da beleza que eles possuem e não têm condições de manifestar (ARANHA, 2006). Nesse caso, o belo e o bom são aspectos de uma só realidade, "que a linguagem corrente dos gregos funde numa unidade, ao designar a suprema arete do homem como ser belo e bom" (JAEGER, 2011, p. 745). Dessa forma, na Antiguidade grega, a Ginástica e a Música, no seu sentido amplo, eram consideradas instrumentos essenciais para o aprendizado, uma vez que propiciavam certa saúde mental e uma harmonia para a alma.

Aristóteles, assim como Sócrates e Platão, foi também um filósofo que se dedicou à atividade educativa e às reflexões em torno da Educação. Na concepção de Aristóteles, a Educação deveria formar os homens para a vida pública e fornecer as condições necessárias para que as pessoas desenvolvessem seus talentos, alcançando a plenitude da realização do seu ser. A finalidade da Educação seria alcançar a felicidade ou o bem, e aquilo que torna o homem feliz, na concepção aristotélica, está no funcionamento da parte mais elevada da natureza humana: a 


\section{Atos de Pesquisa em Educação - ISSN 1809-0354 \\ Blumenau, v. 13, n.2, p.212-228, mai./ago. 2018 \\ DOI: http://dx.doi.org/10.7867/1809-0354.2018v13n2p-212-228}

razão para si, ou seja, a coerência interna de ser e manifestar publicamente aquilo que se é (ARANHA, 2006). O melhor caminho para se alcançar esse objetivo seria por meio da prática da virtude, uma vez que ela, para Aristóteles, está relacionada ao exercício da razão. A ação da vontade conduz ao hábito da virtude. A escola, na concepção de Aristóteles, deveria colaborar para a aquisição deste hábito.

Estes três filósofos gregos - Sócrates, Platão e Aristóteles - influenciaram sobremaneira as reflexões em torno da Educação no que diz respeito a fins, métodos e conteúdos educacionais. Discorrendo sobre as concepções da Paideia nos períodos anteriores, asseguraram a continuidade e a unidade orgânica da cultura grega, sobre ela repousando as ideias da nova concepção filosófica baseada na racionalidade. As ideias de Platão enraizaram-se profundamente na cultura e no pensamento ocidentais, nos quais a Educação estaria associada à cultura do espírito, como um meio de libertar o homem de sua natureza corpórea e mundana, à qual estaria preso. Na concepção filosófica de Platão, que teve por base as ideias de Sócrates, "o sentido e a razão de ser de toda a Paideia é fazer triunfar o Homem dentro do homem" (JAEGER, 2011, p. 746).

Posto isso, não parece impreciso afirmar que, na contemporaneidade, esses valores se encontram dispersos e, em alguns casos, não constituem mais prioridade no projeto da educação de cunho utilitário. Como dito anteriormente, a conjuntura social engendrada no seio da contemporaneidade - que privilegia a atividade instrumental, técnica, o não desperdício do tempo e a valorização da competitividade - demandou da escola projetos de ensino-aprendizagem que se adaptassem a essa realidade, ainda que seja possível observar, em alguns casos, um movimento incipiente de contraponto em direção à formação integrativa.

Pode-se citar como exemplos deste movimento a Escola da Ponte, em Portugal, e as escolas Politeia e Amorim Lima, no Brasil (GRAVATÁ, 2013). Todas elas possuem em comum o fato de serem planejadas para atenderem às suas demandas locais, valorizando o processo individual de cada estudante e fazendo com que ele possa integrar a realidade à sua volta ao que é debatido e construído em sala de aula. Nesses casos, os estudantes se organizam a partir de interesses comuns para desenvolver projetos de pesquisa que estão intimamente ligados aos 


\section{Atos de Pesquisa em Educação - ISSN 1809-0354 \\ Blumenau, v. 13, n.2, p.212-228, mai./ago. 2018 \\ DOI: http://dx.doi.org/10.7867/1809-0354.2018v13n2p-212-228}

seus interesses pessoais (GRAVATÁ, 2013), sem perder de vista os temas propostos pela escola, de modo geral, e pelos professores, de maneira específica.

Em exemplos como esses, é possível dizer que se privilegia o cultivo do conhecimento com sentido em detrimento do simples acúmulo de informação; o reconhecimento da importância da experiência educativa em detrimento da transmissão mecanicista de conteúdos; e a valorização da construção social do conhecimento em detrimento do apelo individualista competitivo observado nos tempos atuais (CORTELLA, 2011; TARDIF, 2010).

No cenário contemporâneo, o individualismo competitivo está atrelado à noção amplamente cultivada de trabalho como um meio de subsistência e valorização social, enxergando-se, nesse caso, a Educação como a ferramenta necessária para que se conquiste uma profissão bem remunerada. É interessante notar que as exigências de mercado eram vistas na Antiguidade como um empecilho à liberdade de espírito necessária à atividade política, à vida justa e plena. $\mathrm{Na}$ contemporaneidade, o trabalho passa a ser glorificado, tornando-se uma virtude; e as atividades educativas que não possuem, mesmo que indiretamente, um sentido de preparação para a conquista de um espaço no ambiente profissional futuro, são vistas como desimportantes. A Educação dos jovens na Antiguidade, baseada na dignidade de ser verdadeiro, na honra e na busca por seus ideais e pelo desenvolvimento de seus talentos, não parece mais necessária: o sucesso profissional e financeiro basta para apontar uma pessoa como bem-sucedida. Ao educando não é necessário mais ser criador e ético, basta-lhe apenas adquirir um conhecimento objetivo que possa ser aplicado futuramente (SALIS, 2008).

Como mencionado anteriormente, é importante esclarecer que levantar tais reflexões não se trata de eleger os atributos da contemporaneidade como equivocados e propor o resgate do modelo da Paideia grega para os dias atuais, na tentativa de "salvar a escola". Obviamente, esse resgate, além de impossível, não seria vantajoso em nenhum aspecto, dado que nossa sociedade atual se configura de maneira muito diferente daquela e exige um padrão diverso do que era antes cultivado. No entanto, para este artigo, parece válido apontar que o modelo da Paideia - e, sobretudo, a educação na Antiguidade - pode despertar reflexões 
Atos de Pesquisa em Educação - ISSN 1809-0354

Blumenau, v. 13, n.2, p.212-228, mai./ago. 2018

DOI: http://dx.doi.org/10.7867/1809-0354.2018v13n2p-212-228

acerca de algumas práticas educativas atuais voltadas para a primazia do utilitarismo.

Com a breve apresentação do modelo da Paideia e a reflexão crítica sobre o viés utilitarista da educação contemporânea, neste artigo, sugere-se que as escolas podem e devem ser espaços de convivência onde os indivíduos desenvolvam seus talentos, seu senso crítico, a sua autonomia, cultivem a responsabilidade social, os valores e a consciência do exercício cidadão (SALIS, 2008). Para a construção de uma sociedade mais justa e igual, essa meta possui vantagens óbvias no âmbito da Educação. No entanto, ela pode entrar em colapso quando a formação humana prioriza o tecnicismo, ou seja, a aplicação direta de conhecimentos objetivos, e desvaloriza a busca de sentido das próprias atividades educativas, tornando os educandos sem direito à expressão de si no contexto das salas de aula, colocandoos no lugar de reprodutores da informação já existente.

A preocupação cada vez maior com o mercado de trabalho e com as incertezas que marcam os empregos na contemporaneidade faz com que os jovens muitas vezes não parem para pensar no seu destino e no que lhes acontece em nível pessoal. O engajamento excessivo da Educação em atividades voltadas para o trabalho pode gerar obstáculos à formação dos educandos, que se veem sem tempo para pensar no desenvolvimento de si ou para contemplar e compreender as consequências da sua mobilização exclusiva para a produtividade.

\section{CONSIDERAÇÕES FINAIS}

A Educação contemporânea, de certa forma, parece se voltar excessivamente à dimensão intelectual e tecnicista do processo de ensino-aprendizagem, enquanto a afetividade, a sociabilidade, a sensibilidade, a expressão artística, salvo raríssimas exceções, têm um papel secundário (PUIG; TRILLA, 2004; SALIS, 2004). Este fato pode ser observado na quantidade de disciplinas e de conteúdos voltados para a dimensão intelectual nos currículos escolares, em comparação com a quantidade de disciplinas e conteúdos que priorizam a afetividade, a sensibilidade, a expressão artística e a Educação Física. Tal primazia, como visto, sugere a aplicação de metodologias tecnicistas de ensino nas quais os educandos atuam como receptores 
Atos de Pesquisa em Educação - ISSN 1809-0354

Blumenau, v. 13, n.2, p.212-228, mai./ago. 2018

DOI: http://dx.doi.org/10.7867/1809-0354.2018v13n2p-212-228

de um conteúdo já existente, o que favorece um contexto de esvaziamento de sentido da experiência de aprender, relegando a segundo plano valores caros a uma formação humana integrativa.

No modelo grego da Paideia, o cultivo da criatividade, da espontaneidade, da autonomia pessoal, da expressão e da sensibilidade - ou seja, a orientação para o ser coerente consigo dentro das possibilidades de cada um - constitui um conjunto de valores que podem se configurar importantes para se repensar a formação humana na contemporaneidade. Voltados para a dimensão afetiva, estes valores nos ajudam a refletir sobre a necessidade de uma educação ética, que prime pela consciência e pela responsabilidade social. Ainda que as instituições educativas convencionais possam resistir a essas mudanças, tais valores harmonizar-se-iam, em melhor medida, em instituições ou meios educativos que tivessem a formação humana integrativa como âmbito de atuação e finalidade.

\section{FABIANA NEIVA VELOSO BRASILEIRO}

Graduada em Psicologia pela Universidade de Fortaleza - UNIFOR. Especialista em Psicologia da Educação pela PUC-MG. Doutora em Psicologia pela UNIFOR.

\section{MARLO RENAN ROCHA LOPES}

Graduado em Psicologia pela Universidade de Fortaleza -UNIFOR. Membro do Laboratório Otium, do Programa de Pós-graduação em Psicologia da UNIFOR.

\section{JOSÉ CLERTON DE OLIVEIRA MARTINS}

Doutor em Psicologia pela Universidade de Barcelona. Pós-doutor pela Universidade de Deusto. Integra o colegiado do Programa de Pós-graduação em Psicologia da Universidade de Fortaleza.

\section{REFERÊNCIAS}

AQUINO, C. A. B.; MARTINS, J. C. de O. Ócio, lazer e tempo livre na sociedade do consumo e do trabalho. Mal-estar e subjetividade, v. 7, n. 2, p. 479-500. 2007.

ARANHA, M. L. A. História da Educação e da Pedagogia. São Paulo: Moderna, 2006.

BAUMAN, Z. Modernidade líquida. Rio de Janeiro: Zahar, 2001. 
Atos de Pesquisa em Educação - ISSN 1809-0354

Blumenau, v. 13, n.2, p.212-228, mai./ago. 2018

DOI: http://dx.doi.org/10.7867/1809-0354.2018v13n2p-212-228

BAUMAN, Z. 44 Cartas do mundo líquido moderno. Rio de Janeiro: Zahar, 2011.

BERIAIN, J. Aceleración y tirania del presente: la metamorfosis en las estructuras temporales de la Modernidad. Barcelona: Anthropos Editorial, 2008.

CORTELLA, M. S. A Escola e o conhecimento: fundamentos epistemológicos e políticos. São Paulo: Cortez, 2011.

GRAVATÁ, A. et al. A Volta ao mundo em 13 escolas: sinais do futuro no presente. São Paulo: Fundação Telefônica, 2013.

JAEGER, W. Paideia: a formação do homem grego. São Paulo: Martins Fontes, 2011.

LARROSA, J. Notas sobre a experiência e o saber de experiência. Revista Brasileira de Educação, v. 19, s/n, p. 20-28. 2002.

LIPOVETSKY, G. Os tempos hipermodernos. São Paulo: Editora Barcarolla, 2004.

LUZURIAGA, L. História da Educação e da Pedagogia. São Paulo: Ed. Nacional, 1979.

MOSÉ, V. A escola e os desafios contemporâneos. Rio de Janeiro: Civilização Brasileira, 2013.

PAVIANI, J. Problemas filosóficos da Educação. Caxias do Sul: Educs, 2010.

PUIG, J. M.; TRILLA, J. A pedagogia do ócio. Porto Alegre: Artmed, 2004.

RODRIGUES, N. Elogio à Educação. São Paulo: Cortez, 2002.

RUSSELL, B. Elogio ao ócio. Rio de Janeiro: Sextante, 2002.

SALIS, V. D. Ócio criador, trabalho e saúde. São Paulo: Editora Claridade, 2004.

SALIS, V. D. Ócio: da Antiguidade ao século XXI. In: CUENCA, M. C.; MARTINS, J.

C. (orgs.). Ócio para viver no século XXI. Fortaleza: As Musas, 2008. p. 9-32.

SALIS, V. D. Projeto Paideia. São Paulo: Edição do Autor, 2011.

TARDIF, M. (2010). Os gregos antigos e a fundação da tradição educativa ocidental. In: GAUTHIER, C.; TARDIF, M. (Orgs.). A pedagogia: teoria e prática da Antiguidade aos nossos dias. Petrópolis: Vozes, 2010. p. 27-60.

COSTA, M. V. A escola tem futuro? Rio de Janeiro: DP\&A, 2003. 